\title{
1.0 mais do que 2.0? O uso tradicional de suportes inovadores nas campanhas eleitorais
}

\author{
Rui Alexandre Novais \\ Doutor em Estudos de Comunicação e Imagem (Universidade de Kent) \\ Professor e Investigador na Universidade do Porto, \\ na Universidade do Minho e na Universidade de Liverpool \\ rualais@gmail.com \\ Viviane Afonso de Araújo \\ Mestre em Ciências da Comunicação (Universidade do Porto) \\ vivisbh@hotmail.com
}

Resumo Este estudo propõe a análise comparativa das campanhas on-line à presidência da República do Brasil (2010) e de Portugal (2011), com o intuito de determinar se os dois candidatos mais bem colocados nas intenções de voto em ambos os países lograram obter o melhor aproveitamento dos recursos de comunicação de campanha pós-moderna, ou da era 2.0. Baseado em uma análise de conteúdo dos tweets dos candidatos no primeiro turno das campanhas nos respetivos países, constatou-se que o Twitter foi primordialmente utilizado como ferramenta de aproximação e comunicação com o eleitor. Na verdade, conclui-se que ainda não se pode falar em uma evolução integral para a terceira era das campanhas políticas, uma vez que os candidatos desperdiçaram o potencial de comunicação bidirecional proporcionado pela interatividade do ambiente digital em detrimento de uma utilização da ferramenta on-line apenas como forma de divulgar as respectivas agendas e propostas. Tal utilização seletiva e instrumental foi feita com o intuito de aumentar a sua visibilidade, mantendo a máxima do período moderno das campanhas baseadas na comunicação orientada no sentido de um para muitos.

Palavras-chave: Twitter, eleições presidenciais, campanha pós-moderna, Portugal, Brasil, participação política, interatividade.

A centralidade da comunicaÇão nas campanhas políticas atuais 1 parece ser indisputável. Em grande medida, tal tem sido possível em virtude da incorporação progressiva das sucessivas inovações no domínio das tecnologias de informação e comunicação no âmbito das estratégias eleitorais (Rommele, 2003). De fato, conscientes de que as campanhas que não se adaptassem aos novos recursos tecnológicos poderiam não ser bem-sucedidas, os partidos e atores políticos têm historicamente otimizado a vertente on-line das suas estratégias eleitorais, adotando, de forma mais ou menos coordenada, os diferentes recursos disponíveis ao longo do tempo (Negrine, 2008).

Contudo, tal inclusão das tecnologias digitais não surge no vácuo e, sim, como complemento de ferramentas tradicionais de campanha já existentes. Nesse contexto, o presente trabalho propõe-se a analisar a utilização das novas mídias num dos momentos fundamentais do processo 
político - as campanhas eleitorais - com o intuito de verificar se os candidatos realmente realizaram uma campanha Web 2.0 empregando todo o potencial dos meios digitais, ou, pelo contrário, se subutilizaram as ferramentas disponíveis, adaptando ao universo digital as estratégias mais tradicionais de campanha. Em especial, pretende-se verificar o espaço concedido no Twitter pelos principais candidatos nas recentes campanhas eleitorais no Brasil (2010) e em Portugal (2011) para a participação e interação com o eleitor, algo que, a verificar-se, constituiria um dos diferenciais das campanhas pós-modernas (Norris, 2004).

Assim sendo, o artigo está dividido em três seções distintas. Na primeira, é proposta uma aproximação contextualizada da literatura relativa ao processo evolutivo da comunicação política de campanha, em geral, e do impacto das redes sociais no âmbito dos momentos eleitorais, em particular. Em um segundo momento, são abordadas as questões do foro metodológico que presidiram presente estudo. Por fim, a análise dos resultados e as implicações das conclusões são consideradas e o argumento proposto, desenvolvido, apontando para a relativização da importância e do impacto das redes sociais nas campanhas, considerando-as apenas uma das ferramentas disponíveis. Na verdade, constata-se, pela análise comparativa das eleições presidenciais portuguesa e brasileira, que o Twitter não foi a ferramenta mais utilizada, nem tampouco a mais decisiva nas estratégias dos principais candidatos nos dois países. Acima de tudo, esta foi empregada como um novo suporte ou plataforma para as antigas estratégias de propaganda eleitoral, a fim de maximizar o voto, desconsiderando os elementos participativos.

\section{As eras da comunicação política de campanha}

A comunicação política de campanha tem sofrido ao longo dos anos um processo evolutivo, acompanhando as significativas mudanças na sociedade e as inovações tecnológicas (Blumler e Kavanagh, 1999). A literatura tende a caracterizar este período progressivo, de forma distinta, em duas grandes categorias, sendo que ambas partilham o fato de serem tripartidas e de proporem diferenciações em termos cronológicos.

A primeira dessas classificações, relacionada com a utilização das mídias e o tipo de organização de campanha, comporta as designações de eras pré-moderna, moderna e pós-moderna (Norris, 2001). No estágio ou era inicial, as campanhas eram caracterizadas por uma relação face a face entre os eleitores e os membros dos partidos, e por eventos de massa que eram organizados por membros mais antigos do partido (Rommele, 2003). De acordo com Pippa Norris
(2004), nas campanhas pré-modernas prevaleciam a organização local, uma forte lealdade do eleitorado, e a mídia partidária seria a responsável por fazer a ponte entre o partido e o eleitor. Consistiam num modelo de campanha concentrado na comunidade local, voltado para as atividades que podiam ser realizadas localmente, como as reuniões de partido e as visitas de casa em casa (Norris,2004).

No que diz respeito à fase das chamadas campanhas modernas, verificou-se um distanciamento entre eleitor e partido, e eleitor e candidato, sendo esse o tipo de campanha que levou ao desinteresse crónico das novas gerações pelos assuntos da política (Norris, 2004). Nesse estágio das campanhas, a comunicação se tornou mais impessoal, voltada para a comunicação de massa, tendo encontrado na televisão seu melhor suporte (Rommele, 2003, p. 8). Já a organização das campanhas propriamente ditas passou a ser coordenada por um grupo de líderes políticos centrais, e foram contratados especialistas em comunicação política e em marketing para planejar e criar os anúncios, organizar a agenda, preparar os eventos e lidar com a imprensa (Norris, 2004, p. 3). Para o eleitor, a experiência da campanha se tornou-se mais distante. Assim, ele deixou em certa medida de ser ator e passou a ser mero espectador (p. 3).

Nas últimas décadas, um terceiro modelo de campanhas tem emergido nas democracias pósindustriais, o qual mereceu diferentes designações: campanhas pós-modernas (Norris, 2000 apud Rommele, 2003, p. 8), terceira fase (Farrel e Webb, 2000 apud Rommele, 2003, p. 8), modelo pósfordista (Denver e Hands, 2002 apud Rommele, 2003, p. 8) e campanhas hipermediáticas (Howard, 2006). Em que pese as diferentes nomenclaturas, todos esses pesquisadores acreditam que se tratava de uma nova fase das campanhas políticas, uma vez que as ferramentas da campanha mudaram com a adoção intensiva das novas tecnologias da comunicação e principalmente com a internet.

Essa terceira era da comunicação política seria igualmente marcada pela fragmentação da televisão, uma vez que os canais a cabo e por satélite e a emissão de notícias durante 24 horas retirariam das campanhas eleitorais um pouco do protagonismo dessas mídias. A oportunidade de interação partido/eleitor proporcionada pela internet obrigou igualmente os partidos a mudarem suas estratégias de comunicação para uma campanha permanente, procurando feedback, por meio de pesquisas de opinião durante todo o tempo, e não apenas durante as eleições (Norris, 2004, p. 6). Esse estágio da modernização das campanhas ainda está em desenvolvimento, estando mais evoluído em alguns países do que em outros (p. 6).

Por outro lado, simultaneamente à distinção anterior, uma outra classificação é proposta pela litera- 
tura, mais em função do recurso e da utilização específica dos meios on-line: pré e pós-internet ou Web 1.0, 2.0 e 3.0 (Vergeer, Hermans e Sams, 2011). As diversas fases refletem a evolução no uso dos recursos on-line, desde os sites individualizados da Web 1.0 para o paradigma do 2.0 do conteúdo gerado pelo utilizador. $\mathrm{Na}$ verdade, enquanto as anteriores eram passivas e apenas convidavam ao download/descarregamento de conteúdos, as 2.0, para além de mais ativas, são dinâmicas, encorajando assim o envolvimento de internautas inclusive no upload de conteúdos (Shuen, 2008). Tais facetas interativas, bidirecionais e descentralizadoras da Web 2.0 assumem implicações particularmente assinaláveis em termos da comunicação política (Hirst e Harrison, 2007).

Para além do foco no líder candidato, e uma maior personalização das mensagens direccionadas a um público mais específico (Vergeer, Hermans e Sams, 2011), o que distinguiria as campanhas Web 2.0 das anteriores seria a integração multimédia, a combinação de consumo e produção, bem como a possibilidade da criação de redes através do estabelecimento de links e RSS feeds (Cormode e Krishnamurthy, 2008). Neste continuum de evolução das campanhas surge, por fim, a referência à Web 3.0, ou web semântica, com recurso vulgarizado a tags de conteúdo, que facilitarão a pesquisa de documentos tornando-a mais rápida e precisa (Iskold e MacManus, 2006).

Neste contexto teórico e assumindo que a comunicação partidária se encontra na atualidade na era da Web 2.0 (Vergeer, Hermans e Sams, 2011), o objetivo do presente trabalho se prende não tanto ao impacto dos recursos on-line em termos de resultado, mas sobretudo em determinar se o padrão de utilização das plataformas sociais dos candidatos nas recentes eleições presidenciais portuguesa e brasileira se enquadra numa lógica mais tradicional de 1.0 ou de 2.0 como instrumento facilitador do contato eleitor/ candidato. Dito de outra forma, pretende-se verificar se os candidatos portugueses e brasileiros utilizaram o Twitter (à semelhança das demais ferramentas on-line) nos parâmetros das campanhas pós-moderna, como instrumento facilitador do contato eleitor/candidato. Desse modo, será possível aferir por que motivo e de que forma os partidos e candidatos integram os novos suportes nas suas estratégias de campanha.

Dando continuidade à questão central de investigação deste trabalho, foi formulada a seguinte hipótese relacionada às expectativas iniciais: apesar de disponíveis, as funcionalidades 2.0 relacionadas com a interatividade não serão plenamente exploradas quer pelos eleitores, quer pelos candidatos, que tenderão a privilegiar as facetas comunicacionais 1.0 possibilitadas pelo Twitter. Antes de iniciar a análise que permite verificar as expectativas que presidiram à investigação, impõe-se, contudo, a clarificação das opções metodológicas.

\section{Questões metodológicas}

Depois do protagonismo dos blogs e do Facebook em atos eleitorais anteriores, no presente trabalho procurou-se aferir o impacto do Twitter nas mais recentes eleições presidenciais no Brasil e em Portugal. A escolha do Twitter residiu no fato de se tratar da mais popular ferramenta de microblog, baseada na divulgação de comentários breves e rápidos de 140 caracteres (ou menos), que combina facetas dos blogs, das mensagens de texto e da transmissão, com imenso potencial de utilização no domínio político. Criado em 2006, o Twitter rapidamente deixou de ser o app $d u$ jour para se converter em algo corriqueiro na vida diária de um número exponencial de utilizadores. Para além da popularidade, o Twitter tem registado um aumento da sua notoriedade através da divulgação em 2009 dos detalhes da aterrissagem de um hidroavião no Rio Hudson ou dos protestos no Irã (Beaumont, 2009, apud Arceneaux e Weiss, 2010).

Tal esforço comparativo transnacional entre os dois principais candidatos à Presidência da República no Brasil e em Portugal, à parte seu ineditismo e utilidade (Esser e Pfetsch, 2004), é também revelador da utilização do Twitter, nas campanhas eleitorais em contextos marcadamente distintos: em termos económicos, culturais e dos próprios sistemas político e midiático, bem como com tradições diferenciadas no recurso às ferramentas on-line, no que se refere às estratégias de campanha. Nesse sentido, a análise pretendeu abordar o nível de participação e a interatividade candidato/eleitor tendo como suporte as timelines constantes nos Twitters oficiais de José Serra, Dilma Rousseff, Manuel Alegre e Cavaco Silva nos dez últimos dias de campanha da primeira fase das respectivas eleições presidenciais.

A metodologia adotada neste estudo consiste na combinação de análise de conteúdo quantitativa e qualitativa. No que concerne à primeira, focalizouse na contabilização dos seguidores registados, bem como na quantidade de mensagens publicadas tanto pelos candidatos quanto pelos seguidores. No que diz respeito à vertente mais qualitativa da análise, concentrou-se numa apreciação da natureza dos tweets com conteúdo informacional ou conversacional (diálogo com os eleitores), numa adaptação da proposta original de Recuero e Zago (2009). O item informacional, por sua vez, foi subdividido em mensagens pessoais (aquelas que tratavam de temas não ligados à campanha ou à política, com linguagem mais informal e espontânea); notícias (que 
referiam à campanha eleitoral); e opinativas e links. Quanto ao item conversacional, este foi subdividido em mensagens diretas e indiretas dos candidatos e dos seguidores. O tweet foi classificado como direto quando o candidato responde diretamente a um seguidor, seja utilizando “@”" ou não, e como indireto quando o candidato publica uma mensagem direcionada a todos os seus seguidores, mas com o intuito de fomentar debate ou respostas (por exemplo, uma pergunta).

\section{Resultados}

\section{Análise quantitativa}

A campanha oficial para a primeira fase das eleições presidenciais brasileiras teve início no dia 6 de julho de 2010 e encerrou-se no dia 30 de setembro do mesmo ano. No entanto, as timelines dos dois principais candidatos à Presidência da República, José Serra e Dilma Roussef, foram analisadas nos dez últimos dias de campanha.

Quadro 1 - Seguidores dos candidatos no Twitter

\begin{tabular}{|l|c|}
\hline Candidatos & Seguidores \\
\hline Dilma Rousseff & 237.000 \\
\hline José Serra & 457.853 \\
\hline Cavaco Silva & 1.350 \\
\hline Manuel Alegre & 815 \\
\hline
\end{tabular}

No final da primeira fase, o candidato José Serra tinha 457.853 seguidores no Twitter, enquanto a candidata Dilma Rousseff contava com 237.000. Em números absolutos, o percentual de seguidores dos dois candidatos é muito alto. Mas, comparados com o número de eleitores brasileiros - cerca de $135 \mathrm{mi}-$ lhões -, os números são ainda residuais.

Conforme se infere da tabela acima, a situação em Portugal não se mostrou muito diferente. Também naquele país as timelines dos dois principais candidatos à Presidência da República, Cavaco Silva e Manuel Alegre, foram analisadas durante dez dias (11 a 21 de Janeiro de 2011), os últimos da campanha oficial.

No final da primeira fase, o candidato Manuel Alegre tinha 815 seguidores no Twitter, enquanto o candidato Cavaco Silva registava 1.350. Os números não deixam dúvida de que os candidatos não conseguiram atrair muitos seguidores. Levando em consideração o número de eleitores portugueses cadastrados, cerca de 9.400.000, os candidatos não conseguiram alcançar nem $1 \%$ do eleitorado. Vale destacar que, desse percentual de eleitores, apenas cerca de $50 \%$ tem acesso à Internet, o que justifica em parte a pouca penetração. Mas, de fato, Manuel Alegre atraiu apenas $0,008 \%$ dos eleitores para seu Twitter e Cavaco Silva, apenas $0,014 \%$.

O pequeno número de seguidores comparado ao número de eleitores deixa claro que o Twitter apesar da sua popularidade, não foi um veículo primordial de comunicação política nas últimas campanhas presidenciais do Brasil e em Portugal. Pelo menos nesse aspecto da interatividade, eles não se enquadram no critério de campanhas pós-modernas de Pippa Norris.

Outros dois critérios de análise utilizados foram o número de mensagens publicadas pelo candidato e o número de mensagens publicadas por seus seguidores.

Quadro 2 - Mensagens postadas no Twitter

\begin{tabular}{|l|c|c|}
\hline Candidatos & $\begin{array}{c}\text { Mensagens dos } \\
\text { candidatos }\end{array}$ & $\begin{array}{c}\text { Mensagens dos } \\
\text { seguidores }\end{array}$ \\
\hline Dilma Rousseff & 11 & 9 \\
\hline José Serra & 102 & 60 \\
\hline Cavaco Silva & 38 & 1 \\
\hline Manuel Alegre & 59 & 1 \\
\hline
\end{tabular}

No período de análise, o candidato José Serra postou 102 mensagens no Twitter, enquanto Dilma publicou 11. Já Manuel Alegre postou 59 tweets, com uma média diária de 4,7 tweets, enquanto seu adversário, Cavaco Silva, publicou 38 mensagens, com uma média de 3,5 tweets por dia. Os candidatos portugueses deram maior atenção ao Twitter às vésperas da eleição, a maior parte das mensagens foi publicado no último dia de campanha oficial, 21 de Janeiro.

Os dados extraídos do quadro de análise comprovam que, de todos os candidatos, José Serra utilizou de maneira mais constante o Twitter. Também os seguidores do candidato do PSDB foram mais participativos, postaram 60 mensagens, por contraposição às 9 da candidata Dilma Rousseff. No entanto, em termos proporcionais, enquanto a quantidade de tweets postados pelos seguidores ultrapassa em pouco a metade dos emitidos por José Serra (58\%), no caso de Dilma, o montante sobe para $82 \%$.

A análise da atividade dos candidatos brasileiros no Twitter pelo site Tweetstats corrobora as informações coletadas no sentido de que o candidato José Serra utilizou mais o microblog em comparação à candidata petista. José Serra postou 276 tweets no mês, uma média diária de 10,6 tweets. Já a candidata Dilma Rousseff publicou apenas 32 mensagens no mês, uma média diária de 1,5 tweets.

No geral, os dados validam a hipótese 1 deste estudo, no sentido de confirmar a participação reduzida nos Twitters oficiais dos principais candidatos eleitorais nas presidências de 2010 no Brasil e de 2011 em Portugal. 


\section{Análise qualitativa}

Num segundo momento, foi realizada uma análise de orientação mais qualitativa de todo o material com o intuito de aprofundar o conteúdo das mensagens publicadas na timeline dos candidatos - quer as postadas pelo próprio, quer pelos seguidores. Desta forma, as mensagens foram classificadas de acordo com dois critérios distintivos: informacional e conversacional.

Quadro 3 - Natureza dos tweets: Informacionais

\begin{tabular}{|l|c|c|c|c|c|c|c|c|}
\cline { 2 - 9 } \multicolumn{1}{c|}{} & \multicolumn{6}{c|}{ TWEETS INFORMACIONAIS } \\
\hline Candidatos & Pessoais & \multicolumn{2}{c|}{ Noticias } & \multicolumn{2}{|c|}{ Opinativos } & \multicolumn{2}{c|}{ Links } \\
\hline $\begin{array}{l}\text { Dilma } \\
\text { Rousseff }\end{array}$ & 2 & $15 \%$ & 9 & $69 \%$ & 1 & $8 \%$ & 1 & $8 \%$ \\
\hline José Serra & 14 & $11.4 \%$ & 52 & $42 \%$ & 4 & $3.3 \%$ & 53 & $42.3 \%$ \\
\hline Cavaco Silva & 0 & $0 \%$ & 38 & $50,7 \%$ & 0 & $0 \%$ & 37 & $49,3 \%$ \\
\hline $\begin{array}{l}\text { Manuel } \\
\text { Alegre }\end{array}$ & 1 & $0.9 \%$ & 58 & $51.3 \%$ & 0 & $0 \%$ & 54 & $47.8 \%$ \\
\hline
\end{tabular}

No que se refere ao candidato José Serra, foram contabilizadas 105 mensagens consideradas informacionais no período de 20 a 30 de setembro de 2010. Verifica-se que o candidato deu maior ênfase às mensagens que tinham como conteúdo o programa de governo, a agenda de campanha, os assuntos relacionados à política nacional, bem como os links para vídeos de campanha e fotos. Ou seja, José Serra priorizou a visibilidade.

Por outro lado, a candidata petista, Dilma Rousseff, utilizou menos o microblog. Durante todo o período de análise, foram postadas 11 mensagens em sua página no Twitter, sendo que a maioria delas (69\%) tinha como objetivo a divulgação de agenda de campanha.

Das 59 mensagens postadas na página do candidato Manuel Alegre, 50\% referia-se à agenda de campanha, ao programa de governo ou às questões políticas de relevância nacional, que à época eram objeto de debate no horário eleitoral gratuito. Dessas mensagens, $49 \%$ ofereciam links para fotos e vídeos do candidato em momentos da campanha. Por exemplo, no dia 18 de janeiro, às vésperas da eleição, quase todos as mensagens publicadas pelo candidato referiam-se à agenda de campanha. O candidato utilizou a ferramenta basicamente como plataforma para a propaganda eleitoral veiculada em outros veículos como Youtube, Facebook ou site oficial (Manuelalegre2011.com). No dia 11 de Janeiro, todos os posts do candidato remetem para vídeos no Youtube, ou material de campanha publicado na sua página oficial. Durante o período de análise, foi postada apenas uma mensagem de cunho pessoal, no dia 17/1, quando o candidato solidariza-se com as vítimas das chuvas no Rio de Janeiro.
O desempenho do candidato Cavaco Silva no Twitter não foi muito diferente de seu adversário. A maior parte das mensagens publicadas $(59,7 \%)$ foi contabilizada como notícias que remetiam à agenda de campanha ou diziam respeito à posição política do candidato sobre algum tema de relevância nacional.

Em virtude da grande quantidade de mensagens com links para sites, redes sociais, fotos e notícias, entendeu-se por bem criar uma tabela especificamente para a subcategoria link.

Quadro 4 - Links constantes nos tweets

\begin{tabular}{|l|c|c|c|c|c|c|c|c|}
\cline { 2 - 9 } \multicolumn{1}{c|}{} & \multicolumn{7}{c|}{ TWEETS COM LINKS } \\
\hline Candidatos & \multicolumn{2}{|c|}{ Links Sites } & $\begin{array}{c}\text { Links Redes } \\
\text { Sociais }\end{array}$ & \multicolumn{2}{c|}{$\begin{array}{c}\text { Links } \\
\text { Notícias }\end{array}$} & \multicolumn{2}{c|}{ Links Fotos } \\
\hline Dilma Rousseff & 0 & $0 \%$ & 0 & $0 \%$ & 0 & $0 \%$ & 1 & $100 \%$ \\
\hline José Serra & 20 & $37.5 \%$ & 10 & $18.9 \%$ & 0 & $0 \%$ & 23 & $43.4 \%$ \\
\hline Cavaco Silva & 4 & $10.8 \%$ & 31 & $83.8 \%$ & 0 & $0 \%$ & 2 & $5.4 \%$ \\
\hline Manuel Alegre & 33 & $61.1 \%$ & 21 & $38.9 \%$ & 0 & $0 \%$ & 0 & $0 \%$ \\
\hline
\end{tabular}

A tabela acima não deixa dúvidas de que especialmente os candidatos portugueses utilizaram o microblog como trampolim para suas páginas oficiais e para outras redes sociais. Os candidatos buscaram aumentar a sua visibilidade e reforçar as mensagens já publicadas nos seus sites, ou durante o horário eleitoral gratuito que foi disponibilizado no Youtube.

No que se refere ao item conversacional (ver Quadro 5), José Serra foi o único candidato que utilizou o espaço no Twitter para responder às perguntas e mensagens de seus seguidores, uma vez que postou 43 mensagens com menções diretas a algum seguidor.

No entanto, vale mencionar que foram contabilizados 60 posts com mensagens de seguidores com perguntas ou manifestações de apoio, ou seja, o candidato não respondeu a todas as mensagens que foram mantidas na sua timeline.

Quadro 5 - Natureza dos tweets: Conversacionais

\begin{tabular}{|l|c|c|c|c|c|c|c|c|}
\cline { 2 - 10 } \multicolumn{1}{c|}{} & \multicolumn{6}{c|}{ TWEETS CONVERSACIONAIS } \\
\hline Candidatos & $\begin{array}{c}\text { Direto/ } \\
\text { Candidato }\end{array}$ & \multicolumn{2}{c|}{$\begin{array}{c}\text { Indireto/ } \\
\text { Candidato }\end{array}$} & $\begin{array}{c}\text { Direto/ } \\
\text { Seguidor }\end{array}$ & \multicolumn{2}{c|}{$\begin{array}{c}\text { Indireto/ } \\
\text { Seguidor }\end{array}$} \\
\hline Dilma Rousseff & 1 & $10 \%$ & 1 & $10 \%$ & 1 & $10 \%$ & 7 & $70 \%$ \\
\hline José Serra & 43 & $39 \%$ & 4 & $4 \%$ & 38 & $36 \%$ & 22 & $21 \%$ \\
\hline Cavaco Silva & 0 & $0 \%$ & 0 & $0 \%$ & 0 & $0 \%$ & 0 & $0 \%$ \\
\hline Manuel Alegre & 0 & $0 \%$ & 0 & $0 \%$ & 0 & $0 \%$ & 1 & $100 \%$ \\
\hline
\end{tabular}

Apesar de muito tímida, em vista do pequeno número de replies aos seus seguidores, a iniciativa foi muito bem recebida pelo eleitorado, que na última semana de campanha colocou o "Pergunteaoserra" no topo do trends Brasil, um ranking de expressões mais 
repetidas no Twitter. A receptividade do candidato e a disposição de atender o eleitorado, aparentemente, despertaram o interesse dos cidadãos em participar, perguntar, comentar, o que evidentemente demonstra a potencialidade da ferramenta quando bem explorada.

O desempenho dos candidatos Dilma Rousseff, Cavaco Silva e Manuel Alegre foi ainda mais desanimador. A candidata brasileira, por exemplo, só respondeu apenas a uma mensagem dos seguidores. Outro dado interessante quanto ao conteúdo das mensagens analisadas no Twitter de Dilma Rousseff é que, durante todo o período, não foi contabilizada nenhuma pergunta de um seguidor. As demais mensagens publicadas pelos internautas (10\%) não tinham como conteúdo perguntas, apenas manifestações de apoio. A petista optou por uma posição neutra no microblog, evitando controvérsias e assuntos polêmicos. No entanto, essa posição suprimiu o que há de mais típico da plataforma, o aspecto conversacional de debate, de troca de ideias em tempo real.

O mesmo ocorreu com os candidatos portugueses. Manuel Alegre não deu nenhuma prioridade para o caráter conversacional da ferramenta. Durante o período de análise, foi publicada apenas uma mensagem indireta de um seguidor e nenhuma mensagem direta ou indireta do candidato com conteúdo conversacional. Também não foi contabilizada nenhuma mensagem de carater conversacional na timeline do candidato Cavaco Silva.

A falta de interação candidato/eleitor perpetuouse durante toda a campanha. Analisando as mensagens, não se verificou nenhuma tentativa de abertura de diálogo, de um espaço para que os cidadãos pudessem esclarecer dúvidas sobre as propostas do candidato à reeleição. Durante todo o período de análise, não foi contabilizada nenhuma mensagem conversacional. Assim como Manuel Alegre, Cavaco Silva privilegiou uma comunicação estática, unidirecional e sem interatividade. Os candidatos utilizaram o Twitter como um folhetim electrónico, mantendo a lógica das plataformas tradicionais de comunicação: um emissor para vários receptores.

Por fim, outros dos parâmetros analisados tiveram como base o tom das mensagens postadas pelos seguidores nos Twitters dos candidatos.

Quadro 6 - Tom das mensagens postadas pelos seguidores no Twitter

\begin{tabular}{|l|c|c|c|}
\hline Candidatos & $\begin{array}{c}\text { Mensagens } \\
\text { positivas }\end{array}$ & $\begin{array}{c}\text { Mensagens } \\
\text { negativas }\end{array}$ & $\begin{array}{c}\text { Mensagens } \\
\text { neutras }\end{array}$ \\
\hline Dilma Rousseff & 9 & 0 & 0 \\
\hline José Serra & 22 & 0 & 33 \\
\hline Cavaco Silva & 0 & 0 & 1 \\
\hline Manuel Alegre & 1 & 0 & 0 \\
\hline
\end{tabular}

De acordo com o Quadro 6, verifica-se que $100 \%$ das mensagens foram positivas ou neutras, uma vez que não foi contabilizada nenhuma mensagem negativa. $\mathrm{Na}$ verdade, o que se pode deduzir é que os candidatos não responderam a mensagens agressivas ou de conteúdo crítico. Eles simplesmente as ignoraram. Assim, para não se ter uma conclusão falsa de que todos os tweets foram positivos ou neutros, prefere-se afirmar que todas as mensagens mantidas pelos candidatos em suas timelines foram positivas ou neutras. Com isso, eles não concederam espaço a críticas ou agressões.

Deste modo, os resultados da análise qualitativa apresentados comprovam que os candidatos presidenciais portugueses e brasileiros privilegiaram as funcionalidades comunicacionais do Twitter em detrimento das conversacionais relacionadas com a interatividade, conforme enunciado na hipótese 2 .

\section{Conclusão}

Num contexto marcado pela centralidade das novas mídias nas campanhas pós-modernas e da Web 2.0, o objetivo deste trabalho consiste em determinar o nível de participação dos eleitores e de interatividade com os candidatos, tendo como suporte as timelines no Twitter dos dois favoritos à presidência no Brasil (José Serra e Dilma Rousseff) e em Portugal (Manuel Alegre e Cavaco Silva). Desse modo, pretende-se aferir o papel da mais popular ferramenta de microblog o Twitter - no sentido de possibilitar uma via de comunicação direta e recíproca entre o candidato e os eleitores como faceta diferenciadora das campanhas pré-modernas, marcadas pelo relacionamento face a face candidato/eleitor; ou, se pelo contrário, o Twitter foi apenas empregado como instrumento da estratégia de propaganda eleitoral, desconsiderando as potencialidades interativas desse microblog.

A primeira constatação que resulta da análise da utilização do Twitter nas recentes campanhas presidenciais é a de que não se pode dizer que Brasil e Portugal, de certo modo, não tenham entrado na terceira era das campanhas políticas, uma vez que os candidatos sob escrutínio utilizam-se das novas tecnologias da comunicação. No entanto, verificou-se que, embora tenham recorrido à internet e às redes sociais nas suas campanhas de forma mais ostensiva do que nas últimas eleições, os candidatos perpetuaram algumas tendências anteriores. Designadamente, os resultados demonstram uma indisponibilidade geral de os candidatos oferecerem ferramentas de participação e interatividade com o eleitor. Apenas o brasileiro José Serra, e de forma despretensiosa, abriu espaço para o diálogo e a interatividade no respectivo microblog, 
respondendo a perguntas e trocando opiniões com seguidores.

Em contrapartida, aquilo que se verificou de forma transversal em ambas as eleições foi que os candidatos privilegiaram o Twitter para divulgação das suas agendas e propostas com o intuito de aumentar a sua visibilidade, preterindo ou desperdiçando o potencial conversacional proporcionado pelo microblog (Recuero e Zago, 2009). Na verdade, as mais recentes eleições presidenciais no Brasil e em Portugal revelaram uma utilização seletiva do Twitter como um trampolim para as páginas no Facebook ou para os respectivos sites oficiais dos candidatos, sendo isso revelador de que a ferramenta de microblog foi tratada como uma plataforma adicional para as práticas habituais do universo off-line (Graeff, 2009).

Do exposto, resultam algumas implicações fundamentais dignas de consideração. Desde logo, confirma-se a tendência de convergência (ainda que parcial) das técnicas e estratégias de campanha no que diz respeito à utilização de novas mídias em países pertencentes a diferentes sistemas político-mediáticos. Em segundo lugar, comprova-se que tanto Brasil quanto Portugal já estariam na chamada era das campanhas pós-modernas (Norris, 2004), ainda que o Twitter tenha sido utilizado apenas de forma marginal e complementar, como um novo suporte ou plataforma para as antigas estratégias de propaganda eleitoral. Por conseguinte, perma-

\section{Referências}

ARCENEAUX, Noah; WEISS, Amy Schmitz. Seems stupid until you try it: press coverage of Twitter, 20062009. New Media \& Society, v. 12, no 8, p. 1262-1279, 2010. BIMBER, Bruce; DAVIS, Richard. Campaigning online: The Internet in U. S. elections. Oxford: Oxford University Press, 2003.

BLUmleR, G. Jay; KAVANAGH, Dennis. The Third Age of Political Communication: Influences and Features. Political Communication, v. 16, p. 209-230, 1999.

CHADWICK, Andrew ; MAY, Christopher. Interaction Between States and Citizens in the Age of the Internet: "E-Government" in the United States, Britain and the European Union. Governance, v. 16, nº 2, p. 271-300, 2003. COMM, Joel. O poder do Twiter - estratégias para dominar seu mercado e atingir seus objetivos com um tweet por vez. São Paulo: Gente, 2009.

CORMODE, Graham; KRISHNAMURTHY, Balachander. Key differences between Web 1.0 and Web 2.0. Graham Cormode. First Monday, v. 13, nº 6, 2008. Disponível em: http://www.uic.edu/htbin/cgiwrap/bin/ojs/index.php/ fm/article/view/2125 Acesso em: 20 set. 2010.

ESSER, Frank; PFETSCH, Barbara. Comparing Political Communication: theories, cases, and challenges. Cambridge: Cambridge University Press, 2004. nece a utilização do tipo top down das novas tecnologias da comunicação, a fim de maximizar o voto, colocando os elementos participatórios em segundo plano. $\mathrm{Na}$ verdade, os partidos parecem ter dificuldade em abandonar a estrutura hierarquizada e extremamente centralizada de dirigir a campanha, característica do período moderno. Sobretudo, no que diz respeito à falta de interatividade ou de diálogo entre o candidato e o eleitor, que, sendo a principal faceta diferenciadora proporcionada pelas redes sociais (Bimber e Davis, 2003; Gomes, 2005; Recuero e Zago, 2009; Garcia, 2010; e Comm, 2009), não foi contudo melhor aproveitado em termos de possibilidades interativo-comunicativas (Smith, 1999; e Chadwick e May, 2003). Por fim, se confirma que o Twitter não merece ainda a atenção que rivalize com outros recursos de campanha considerados como sendo os mais eficazes e adequados aos respectivos contextos eleitorais, uma vez que as novas mídias ainda acarretam imprevisibilidades e riscos acrescidos em comparação a métodos tradicionais mais eficazes, já testados e comprovados. Tal constatação corrobora a tendência da utilização dos recursos de campanha de forma enviesada e preferencial, de acordo com os principais objetivos eleitorais. Em suma, prevaleceu a decisão baseada no custo-benefício aliada aos receios e perigos de perda de controle da mensagem (Stromer-Galley, 2000 e 2003) em detrimento da interatividade (Rommele, 2003).

GARCÍA, Ana María Álvarez. Principales efectos y ventajas del uso de las nuebas tecnologias en campañas electorales. CIC Cuadernos de Información y Comunicación, v. 15, p. 55-84, 2010. Disponível em: http://revistas.ucm.es/inf/11357991/ articulos/CIYC1010110055A.PDF Acesso em: 11 fev. 2011. GOMES, Wilson. A democracia digital e o problema da participação civil na decisão política. Brasil: Revista Fronteiras - estudos midiáticos, v. VII , nº 3, p. 214-222, 2005. GRAEFF, Antônio. Eleições 2.0: a internet e as mídias sociais no processo eleitoral. São Paulo: Publifolha, 2009. HIRST, M.; HARRISON, J. Communication and New Media: From broadcast to narrowcast. South Melbourne: Oxford University Press, 2007.

HOWARD, Philip. New Media Campaigns and the Managed Citizen. New York: Cambridge University Press, 2006.

ISKOLD, A.; MACMANUS, R. The Road to the Semantic Web. Blog article, 2006, November 14. Disponível em: http://www.readwriteweb.com/archives/semantic_web_ road.php Acesso em: 10 out. 2011.

NEGRINE, Ralph. The Transformation of Political Communication. 1. ed. London: Palgrave Macmillan, 2008. NORRIS, Pippa. The Evolution of Election Campaigns: Eroding political engagement? Cambridge, MA: Harvard University Press, 2004. 
NORRIS, Pippa. Digital Divide: Civic Engagement, Information Poverty and the Internet Worldwide. Cambridge, MA: Cambridge University Press, 2001.

RECUERO, Raquel; ZAGO, Gabriela. Em busca das "redes que importam" - Redes sociais e capital social no Twitter. São Paulo: Compôs, 2009. p. 1-16. Disponível em: http://www.compos.org.br/data/trabalhos_arquivo_ coirKgAeuz0ws.pdf Acesso em: 4 abr. 2011.

ROMMELE, Andrea. Political Parties, Party Communication and New Information and Communication Technologies. London: Thousand Oaks; New Delhi: Party Politics, v. 9. $\mathrm{n}^{\circ} 1,2003$.

SHUEN, Amy. Web 2.0: A Strategy Guide: Business thinking and strategies behind successful Web 2.0 implementations. Sebastopol: O’Reilly Media, 2008.

SMITH, Marc. Invisible Crowds in Cyberspace: Mapping the Social Structure of the Usenet. In: SMITH, M. A.; KOLLOCK, P. (Eds.). Communities in Cyberspace. London: Routledge, 1999. p. 195-219.

STROMER-GALLEY, Jennifer. On-line interaction and why candidates avoid it. Journal of Communication, $\mathrm{n}^{\circ}$ 50, p. 111-132, 2000.

STROMER-GALLEY, Jennifer. Diversity of Political Conversation on the Internet: Users' Perspectives. Journal of Computer-Mediated Communication, v. 8, n $\mathrm{n}^{\circ}$ 3, 2003. Disponível em: http://jcmc.indiana.edu/vol8/issue3/ stromergalley.html Acesso em: 11 mar. 2011.

VERGEER, Maurice; HERMANS, Liesbeth Hermans; SAMS, Steven. Is the voter only a tweet away? Microblogging during the 2009 European Parliament election campaign in the Netherlands. First Monday, v.16, $\mathrm{n}^{\circ} 8$, 2011.

\title{
1.0 more than 2.0? The traditional usage of innovative tools in election campaigns
}

\begin{abstract}
This study presents a comparative analysis of 2011 Portuguese and 2010 Brazilian presidential on-line campaigns, aiming to determine whether the two best poll-positioned candidates, in both countries, managed to make a considerable use of the communication resources of post-modern campaign. Based on a content analysis of messages posted by the candidates during the first round of elections, it was concluded that the Twitter was primordially used to approximate and communicate with the voters. It was also observed we cannot talk about an integral evolution to the political campaign third era, once the candidates missed out the bidirectional communication potential made available by the digital environment interactivity and used the on-line tool simply to publicize their agendas and proposals in order to increase their visibility.
\end{abstract}

Key words: Twitter, presidential elections, post-modern campaign, Portugal, Brazil, political participation, interactivity.

\section{0 más que 2.0? El uso tradicional de suportes innovadores en campañas electorales}

\section{Resumen}

Este estudio propone una análisis comparativa de las campañas on-line a la presidencia de Brasil (2010) y de Portugal (2011) con el intuito de determinar si los dos candidatos mejor colocados en las intenciones de voto en ambos países han rentabilizado los recursos de comunicación de campaña pos-moderna o de la era 2.0. Basado en un análisis de contenido de los tweets de los candidatos en la primera vuelta de las campañas en sus respectivos países, se constata que el Twitter ha sido primordialmente utilizado como herramienta de aproximación y comunicación con el elector. Se concluye que no hay aún una evolución integral para la tercera era de las campañas políticas una vez que los candidatos han desaprovechado el potencial de comunicación bidireccional proporcionado por la interactividad del ambiente digital, optando por una utilización de la herramienta on-line apenas como una forma de divulgar las respectivas agendas y propuestas. Tal uso selectivo y instrumental apuntaba a aumentar su visibilidad y manteniendo la máxima del período moderno de las campañas de una comunicación de un para muchos.

Palabras-clave: Twitter, elecciones presidenciales, campaña posmoderna, Portugal, Brasil, participación política, interactividad. 